\title{
Consecuencias adversas a la legítima defensa propia e impropia como causa de justificación
}

\author{
The adverse consequences of perfect and \\ imperfect self-defense as a cause of justification \\ 0 (1) \\ EPIFANIO LÓPEZ CANTORAL \\ Universidad Nacional Mayor de San Marcos \\ (Lima, Perú) \\ Contacto: epifanio.lopez@unmsm.edu.pe \\ https://orcid.org/0000-0003-4704-2665
}

\section{RESUMEN}

La legítima defensa - propia e impropia - es un instituto jurídico de defensa de bienes jurídicos propios o de terceros, que opera frente a una agresión ilegítima, actual o inminente, que debe concurrir con los requisitos que prevé el artículo 20, inciso 3, del Código Penal vigente. Asimismo, usar el derecho a la legítima defensa como justificación a veces trae consigo consecuencias adversas no previsibles, como el daño o la lesión a bienes jurídicos de terceros, por ejemplo, la muerte o lesión de personas. Entonces, conlleva asumir la responsabilidad contra el accionante o el accionado, respectivamente. Más aún, ejercer tal derecho debe ser de 
última ratio, no de primera línea. En tal sentido, usarlo implica ser cuidadoso y responsable en cada circunstancia particular. Por ejemplo: no es lo mismo ejercer la legítima defensa sin que haya presencia de personas, que ejercerla en lugares con presencia de ellas.

Palabras clave: legítima defensa; bienes jurídicos; consecuencias adversas; causa de justificación.

\section{ABSTRACT}

Self-defense -proper and improper- is a legal institute for the defense of one's own or third parties' legal interests, which operates in the face of a current or imminent unlawful aggression, which must meet the requirements outlined in article 20, paragraph 3 , of the Criminal Code in force. Also, using the right to self-defense as a justification sometimes results in unforeseeable adverse consequences, such as damage or injury to the legal interests of third parties, for example, death or injury to persons. In this sense, using it implies being careful and responsible in each particular circumstance. For example, it is not the same to exercise self-defense in the presence or absence of the persons involved.

Key words: self-defense; legal interests; adverse consequences; cause of justification.

Recibido: 15/05/2021 Aceptado: 26/05/2021

\section{INTRODUCCIÓN}

En principio, la legítima defensa es una institución jurídica de carácter universal reconocida en muchas legislaciones del mundo. El Perú no es ajeno a ella. Esta institución está normada en el artículo 20, inciso 3, del Código Penal vigente. Asimismo, se trata 
de uno de los temas que ha generado mayor debate doctrinario respecto de su regulación y aplicación normativa a nivel nacional e internacional. Ahora bien, la legítima defensa está catalogada como un derecho fundamental regulado en el artículo 2, inciso 3, de la Constitución Política vigente. Ahí radica el punto de partida para justificarla ante una eventual amenaza o puesta en peligro de bienes jurídicos tutelados. Entonces, la regulación normativa debe cumplirse como lo señala el Código Penal.

La doctrina especializada ha referido que entre los problemas patentes están los requisitos que deben cumplirse, así como los bienes defendibles que abarca. Por ello, el mayor debate se ha centrado en los requisitos exigidos por la norma penal, que suele presentar figuras alternas como la legítima defensa incompleta, el exceso a esta, entre otras. Por otro lado, Cerezo (1998) postula que

el derecho a la legítima defensa lleva implícito un precepto permisivo que interfiere en las normas de carácter general, dando lugar -en el caso más habitual- a que una conducta prohibida, que menoscaba un interés tutelado por el derecho, no sea desaprobada por el ordenamiento jurídico y, en consecuencia, resulte lícita por exclusión de su antijuricidad (p. 189).

Mientras que Revilla (2015) anota:

la antijuricidad, entendida como la propiedad de una conducta de ser contraria al derecho, es enervada por la legítima defensa; por ello, aunque sea la sede penal su ámbito por antonomasia, el ejercicio del derecho constitucional a la legítima defensa debe excluir la antijuricidad de la conducta en el ordenamiento jurídico en su conjunto (p. 351).

Además de lo señalado, una de las consecuencias que ha generado la legítima defensa es la adversidad al derecho invocado. Es decir, usar dicha institución para salvaguardar derechos e intereses 
propios o de terceros, frente al peligro o la afectación de bienes tutelados, trae consigo una respuesta negativa de quien hace la defensa. Esto es básicamente la muerte o lesión de alguna persona ajena, o algún daño patrimonial producto del «enfrentamiento» entre el agresor y el agredido.

Lo señalado es una realidad que no debe ser desatendida. Incluso tendrían que existir lineamientos o protocolos que deberían tomarse en cuenta para quien invoca la legítima defensa, considerando el riesgo que genera el uso de este derecho. Es decir, se debe determinar cuál es la respuesta idónea para aquellas personas que por circunstancia ajena sufriesen algún daño a la integridad personal o patrimonial. En este escenario, podría sostenerse una responsabilidad compartida. En su defecto, la responsabilidad debe ser asumida por la persona que realiza la agresión, lo cual se ve en contadas oportunidades.

En ese sentido, el presente trabajo tiene como objetivo determinar las posibles consecuencias del empleo de la legítima defensa. Posibles porque caben los escenarios en que no se concreten. Asimismo, se tocarán tres requisitos indispensables sin los cuales no podría ser invocada. Vale decir, para una válida configuración de la legítima defensa deben concurrir los tres requisitos regulados en la normativa penal: agresión ilegítima, necesidad racional del medio empleado para impedirla o repelerla, y falta de provocación suficiente de quien hace la defensa. Finalmente, se dará a conocer la posición sobre esta institución de suma importancia en la coyuntura social.

\section{LA LEGÍTIMA DEFENSA}

Conviene recordar algunos conceptos de la legítima defensa: «repulsa de la agresión ilegítima, actual o inminente, por el atacado o tercera persona, contra el agresor, sin traspasar la necesidad de la 
defensa y dentro de la racional proporción de los medios empleados para impedirla o repelerla» (Jiménez de Asúa, 1939, p. 556) y «defensa necesaria para rechazar una agresión actual o inminente e injusta, mediante un acto que lesiona bienes jurídicos del agresor» (Cuello, citado por Zambrano, 2006, p. 261).

Resulta claro que la legítima defensa es una causa de justificación atribuida a quien hace la defensa de bienes jurídicos propios o de terceros frente a una agresión injustificada, lo que conlleva a ejercitar la acción defensiva para salvaguardar los derechos o los intereses correspondientes. Además, la legítima defensa opera en salvaguarda de derechos comunitarios o sociales. Asimismo, es un derecho defensivo que asiste a toda persona que se encuentra frente a una agresión ilegítima, actual o inminente, proveniente del que obra o de un tercero, dado que es susceptible de lesionar bienes jurídicos tutelados. Dicha agresión se justifica si no fue provocada por quien ejerce la acción defensiva. Además, la legítima defensa es una autoprotección jurídico penal y una reacción necesaria frente a un peligro inminente que se puede manifestar directa e indirectamente:

Así pues, la defensa cumple no solo una función de protección de bienes jurídicos, sino también, al afirmar y hacer prevalecer el Derecho frente al injusto agresor, si es preciso con una tremenda dureza, una importante función de prevención general: de intimidación frente a delincuentes y de prevalecimiento del orden jurídico, creando seguridad de los ciudadanos en el mismo. Es más, por su contundencia, que incluso puede llegar a la muerte del agresor, y por no ser una eventual reacción a posteriori, sino algo que hace fracasar la agresión en el momento decisivo, la legítima defensa puede ser, sobre todo si se emplea con frecuencia, un medio intimidatorio tanto o más eficaz que la pena (Luzón, 2006, p. 526). 
Ahora bien, los alcances de la legítima defensa se basan en una agresión ilegítima, una racionalidad del medio empleado para ejercer la defensa y la falta de provocación suficiente de quien hace la defensa. Para la doctrina mayoritaria, se trata del inicio de una reacción legítima, la misma que es una fuerza material para repeler una agresión ilegítima que atente nuestra integridad o la de terceros, o si se quiere decir, contra cualquier bien jurídico tutelado.

Finalmente, es preciso señalar que existe un consenso a nivel de la doctrina penal, que estima que todos los bienes jurídicos son defendibles: la vida, la libertad y la integridad personal propia o de un tercero. Además, se considera la protección al patrimonio, el domicilio, la morada, etc. También son bienes defendibles la colectividad o la comunidad, respectivamente. En efecto, es pasible emplear la legítima defensa en pro de salvaguardar los derechos e intereses personales o de terceros.

\section{LA CAUSA DE JUSTIFICACIÓN}

En sentido lato, las causas de justificación son aquellas que excluyen la antijuricidad o ilicitud de la conducta típica, es decir, se trata de una conducta sujeta a derecho. Se traduce en una situación objetiva y subjetiva de quien se defiende. Entre ellas tenemos a la legítima defensa, el estado de necesidad justificante y el consentimiento. Ahora bien, Villegas (2014) señala que

las causas de justificación operan como estructuras de descargo de la imputación, pues la conducta desplegada en esos supuestos concretos abarcados por las causas de justificación, se la considera conforme a derecho, es decir, no se habría creado un riesgo prohibido susceptible de sanción penal, sino que se trataría de un riesgo permisible (pero solo en esas especiales circunstancias) (p. 74). 
Mientras que Muñoz y García (2010) consideran que

las causas de justificación tienen elementos objetivos y subjetivos. Para justificar una acción típica no basta con que se dé objetivamente la situación justificante, sino que es preciso, además, que el autor conozca esa situación e, incluso, cuando así se exija, que tenga las tendencias subjetivas especiales que exige la ley para justificar su acción (pp. 312-313).

En efecto, en la causa de justificación se activa una respuesta jurídico penal de autoprotección frente a conductas externas desaprobadas por la ley penal. Dicha respuesta debe estar vinculada al conflicto entre la posible afectación de algún bien jurídico y la tutela de este, pero con la aprobación de los requisitos exigidos por el artículo 20, inciso 3, del Código Penal. Si no fuese el caso, o faltase algún requisito, recae en el artículo 21 del Código Penal, como responsabilidad atenuada.

\section{REQUISITOS DE LA LEGÍTIMA DEFENSA}

Los requisitos legales están previstos en el artículo 20, inciso 3, del Código Penal vigente, el cual señala:

El que obra en defensa de bienes jurídicos propios o de terceros, siempre que concurran las circunstancias siguientes:

a. Agresión ilegítima;

b. Necesidad racional del medio empleado para impedirla o repelerla. Se excluye para la valoración de este requisito el criterio de proporcionalidad de medios, considerándose en su lugar, entre otras circunstancias, la intensidad y peligrosidad de la agresión, la forma de proceder del agresor y los medios de que se disponga para la defensa;

c. Falta de provocación suficiente de quien hace la defensa (Poder Ejecutivo, 1991). 
Entonces, es de suma importancia discernir lo antes señalado, en razón del cumplimiento estricto de los requisitos previstos. Sin la concurrencia de estos, no sería posible invocar la legítima defensa.

\subsection{La «agresión ilegítima»}

\subsubsection{Concepto}

Por agresión se entiende:

cualquier ataque a bienes jurídicos o derechos cuyo titular sea una persona [...] la agresión tiene que suponer un peligro serio e inminente de lesión del bien jurídico de que se trate. No basta con una lejana percepción del peligro por parte de la víctima; el peligro debe ser real, serio y grave (en el sentido de que puede menoscabar el bien jurídico) (Berdugo, Arroyo, García, Ferré y Serrano, 1999, p. 227).

Y «la agresión, [...] la amenaza de lesión, mediante una acción humana de intereses vitales jurídicamente protegidos» (Welzel, 1956, p. 91).

Por lo tanto, el punto de partida es la conducta humana. Si esta no existiese, no sería posible admitir la legítima defensa. Por ejemplo, la agresión de animales como el perro, a contrario sensu, procede cuando aquel es instruido o azuzado por el dueño. Tampoco sería admitida la agresión en casos de fuerza física irresistible, inconciencia o acto reflejo, lo que conllevaría a un estado de necesidad. Asimismo, no es posible la legítima defensa - agresiónsi se trata de tentativa inidónea, como cuando alguien no saca el arma con la intención de azuzar al médico o enfermo, sino para disparar al cadáver que acaba de fallecer.

Según García (2019):

no hay impedimento para que la agresión se realice también mediante una omisión, siempre que esta sea penalmente relevante por existir una posición de garantía atribuida al omitente 
(omisiones impropias). Esa posición de garantía puede ser de carácter organizativo o institucional. Ejemplos de agresiones omisivas serían el dueño que no detiene el ataque de su perro (competencia por organización) o la madre que no alimenta al recién nacido (competencia institucional) (p. 616).

En la doctrina dominante, se discute la situación de los menores de edad, epilépticos, locos, ebrios, sonámbulos o de quienes actúan por error, entre otros casos, dada la particularidad de su accionar humano. Sin embargo, cabe la posibilidad de ejercer la legítima defensa contra ello. En ese contexto, se descarta la posibilidad de agresión en aquellas conductas antisociales, éticas o morales que provengan de gestos o señales del cuerpo humano. Asimismo, «no hay agresión» en agresiones justificadas, como las que se producen en riñas, entre animales, en agravios verbales mutuos, entre otros casos.

Entonces, la agresión debe consistir en un comportamiento humano que lesione o ponga en peligro bienes jurídicos tutelados propios o de terceros. Dicha agresión debe ser actual, ilegítima y real, lo que implica violencia o amenaza. Además, la agresión debe ser objetiva y no subjetiva. Para Villegas (2014), «en la agresión ilegítima se contempla únicamente la presencia de una acción humana antijurídica. No se requiere que dicha conducta se subsuma dentro de un tipo penal, en tanto la legítima defensa actúa contra cualquier interés jurídicamente protegido» (p. 76).

\subsubsection{Características de la «agresión ilegítima»}

Encontramos cinco características:

1. La agresión siempre como acto humano. Reiterando supra, la agresión debe ser una conducta humana, sea imputable o no. Esto descarta la agresión de animales, cosas, etc. Entonces, el accionar de una persona se da con pleno conocimiento y voluntad - o con la ausencia de ellos- de afectar o vulnerar bienes jurídicos tutelados propios o de terceros. 
2. Actualidad de la agresión. Como bien señala Cuello (1976), «ha de ser actual e inminente. Antes que el peligro aparezca no es necesaria la defensa, cuando ha cesado es superflua. Basta que la agresión esté próxima a realizarse» (p. 357) y como plantea Bramont-Arias:

no puede haber legítima defensa después de haber terminado la respectiva agresión, de lo contrario estaríamos situándonos ante un abuso de derecho, que podrían afrontarse en venganza o justicia por mano propia. Asimismo, el ataque deberá de ser inminente cuando la resolución del agresor sea irrevocable respecto al inicio del ataque; no podría llamarse inminente aquella acción jurídicamente imposible, así pues, una persona no podría agredir a otra con un mazo de plástico para piñata (no existiría agresión si esta es una tentativa inidónea) (Pérez, pp. 99-100).

El término «actual» alude al tiempo presente, mientras que «inminente» es una situación que amenaza con suceder de manera inmediata. Dado que representa una situación de peligro, se legitima la conducta. Asimismo, la acción defensiva puede subsistir en tanto permanezca la agresión. Si esta concluye, no se puede generar una nueva agresión ni accionar la legítima defensa.

3. Ilegitimidad de la agresión. Sobre esta, Mir (2008) propone que

equivale a agresión antijurídica. Ello significa que no basta que sea típica, pero también que no es preciso que sea personalmente imputable a su autor: cabe también legítima defensa frente a la agresión antijurídica de un inimputable o de quien actúa bajo una causa de exculpación (p. 438).

Con la antijuricidad de la agresión, el agredido no puede soportar jurídicamente una acción no autorizada, es decir, no es posible soportar la agresión ilegítima. Asimismo, para esta última es ineludible que exista un bien jurídico amenazado. Como bien señala 
la doctrina dominante, la agresión no solo se refiere a los bienes jurídicos protegidos, sino también a cualquier interés jurídicamente protegido. En este escenario, no es posible admitir la legítima defensa contra legítima defensa. La conducta de quien hace la defensa está sujeta a derecho y está invocada por una causa de justificación.

4. Realidad de la agresión. Se presenta una existencia real y no imaginaria. Es decir, la agresión debe ser objetiva y creíble, y debe amenazar algún bien jurídico tutelado. A contrario sensu, estamos ante una legítima defensa putativa, lo que representa suposiciones o meras conjeturas de su real afectación.

5. Bienes defendibles. Puede ser cualquier bien jurídicamente protegido. Por ejemplo, la vida, la integridad, la libertad, etc. También derechos patrimoniales propios o de terceros, como la morada, el domicilio y, finalmente, el honor de las personas.

\subsubsection{Legislación comparada}

Según el Código Penal argentino:

ARTÍCULO 34.- No son punibles:

$[\ldots]$

$6^{\circ}$. El que obrare en defensa propia o de sus derechos, siempre que concurrieren las siguientes circunstancias:

a) Agresión ilegítima (Congreso de la Nación Argentina, 1984).

Mientras que de acuerdo con el Código Penal colombiano:

Artículo 32. Ausencia de responsabilidad. No habrá lugar a responsabilidad penal cuando:

[...]

6. Se obre por la necesidad de defender un derecho propio o ajeno contra injusta agresión actual o inminente, siempre que la defensa sea proporcionada a la agresión (Congreso de la República de Colombia, 2000). 


\subsection{Necesidad racional del medio empleado para impedir 0 repeler La agresión}

En principio, este requisito está previsto en el artículo 20, inciso 3, literal b, del Código Penal vigente. Presentado correctamente el primer requisito de la norma, sigue el análisis del presente para una válida configuración de la legítima defensa. Entonces, la «necesidad racional del medio empleado» no debe entenderse como proporcionalidad de medios (revólver contra revólver, sable contra sable, puño contra puño, etc.), sino que hace alusión al propio medio necesario para frenar o evitar la agresión ilegítima. Este requisito ha sido un tema controvertido en la doctrina dominante y ha llevado a interpretaciones disparejas y poco coherentes. Dada la última reforma penal, estaría resuelta la problemática respecto del segundo inciso.

Como señala Roxin (1997):

el defensor debe elegir, de entre varias clases de defensa posibles, aquella que cause el mínimo daño al agresor. Pero para ello no tiene por qué aceptar la posibilidad de daños en su propiedad o de lesiones en su propio cuerpo, sino que está legitimado para emplear como medios defensivos los medios objetivamente eficaces que permitan esperar con seguridad la eliminación del peligro (p. 628).

Básicamente, la necesidad racional del medio empleado debe estar en función de cada circunstancia en particular. Sostengo que no es tan fulminante saber y emplear que la conducta agresiva sea repelida con un medio menos lesivo. Por ejemplo, si una persona robusta se enfrenta a una persona delgada, vencerá el primero. En ese escenario, si el segundo tiene a su alcance un cuchillo, debe emplearlo sin más remedio. Así también sucede cuando se utilizan armas de fuego y armas blancas. 
Ahora bien, lo racional «hace suficiente una necesidad aproximada, no estricta para cualquier persona de las características del autor colocada en su situación en el momento de defenderse (consideración ex ante)» (Mir, 2008, p. 436). Asimismo, el término «racional» debe entenderse como razonable, un aproximado entre el ataque y la defensa, lo cual no implica un cálculo aritmético. Además, la racionalidad del medio empleado no puede someterse al principio de "proporción equitativa».

\subsubsection{Exclusión del criterio de proporcionalidad de medios}

Como ya dijimos antes, en principio, la proporcionalidad de medios estaba referida a la igualdad de medios empleados, es decir, quien hace la defensa debe emplear el medio igual al medio empleado por el agresor. Entonces, la actual regulación normativa ha sido modificada en cuanto a la proporcionalidad de medios, considerando en su lugar otros criterios. Entonces, en buena cuenta, ha sido un avance significativo para proteger los derechos e intereses del agredido y, por supuesto, de terceros.

\subsubsection{Intensidad de la agresión}

Debemos entender por «intensidad» al grado de fuerza con que se manifiesta el agresor, es decir, representa una magnitud física, anímica o una cualidad especial de agresividad. Lo que conlleva a ejercer la legítima defensa en pro de salvaguardar los derechos e intereses propios o de terceros.

\subsubsection{Peligrosidad de la agresión}

Implica que el accionar del agente o agresor pueda causar o generar daños, riesgo o amenaza a la integridad corporal de la víctima, así como a la esfera patrimonial. En suma, también se da para cualquier bien jurídico tutelado por la norma vigente. 


\subsubsection{Forma de proceder del agresor}

Viene a ser el modo o la forma de accionar de la conducta en menoscabo de los bienes jurídicos protegidos, que puede variar la forma acorde a cada circunstancia. Esta representa en el agredido una agresión inminente, actual y real y, desde luego, se efectúa una reacción lógica en defensa de bienes y derechos propios o de terceros.

\subsubsection{Disponibilidad de medios para la defensa}

Implica que el agredido o víctima disponga en su entorno de cualquier medio, y que está listo para ser utilizado contra el agresor en defensa de los bienes jurídicos tutelados. Es válido cualquier medio disponible, y que no existan otros medios alternos para la defensa, por ejemplo: desde el uso de una piedra hasta el uso de un arma de fuego.

\subsubsection{Legislación comparada}

De acuerdo con el Código Penal argentino:

Artículo 34.- No son punibles

[...]

6. El que obrare en defensa propia o de sus derechos, siempre que concurrieren las siguientes circunstancias:

[...]

b) Necesidad racional del medio empleado para impedirla o repelerla (Congreso de la Nación Argentina, 1984).

Mientras que para el Código Penal chileno:

Art. 10. Están exentos de responsabilidad criminal:

[...]

$4^{\circ}$. El que obra en defensa de su persona o derechos, siempre que concurran las circunstancias siguientes: 
[...]

Necesidad racional del medio empleado para impedirla o repelerla (Congreso Nacional de Chile, 1874).

\subsection{Falta de provocación suficiente de quien hace la defensa}

El tercer requisito está previsto en el artículo 20, inciso 3, literal c, del Código Penal vigente. Entonces, cumplidos los primeros requisitos de la norma, ello nos lleva al análisis del presente, por consiguiente, constituye legítima defensa como tal.

La provocación puede consistir tanto en una conducta voluntaria como imprudente de quien pretende luego ejercer la acción defensiva. No puede restringirse a una provocación dolosa, pues se estaría recortando de forma injustificada la protección de los bienes jurídicos fundamentales, por quien es provocado ilegítimamente. La acción no es preciso que esté dirigida al fin de desencadenar la respuesta agresora (Peña, 2011, p. 683).

Este requisito implica el castigo de una acción de defensa racional y necesaria frente a una agresión ilegítima. Es decir, el agredido que se defiende no de haber provocado la agresión al agresor. Bien podría darse el caso de una agresión grave e intencional (provocación suficiente e insuficiente), en esta última, de sobrepasar los límites permisibles, podría incluso ocurrir una "contraagresión», en la cual perfectamente podría darse la legítima defensa.

Claro está, nadie tiene derecho a agredir, tampoco hay derecho a sobrepasar los límites permisibles en una agresión intencional o insuficiente. Como señalé anteriormente al tocar el tema de la «agresión ilegítima», no hay agresión, vale decir, en agresiones justificadas, en agresiones en riña, en agresiones mutuas, etc., pero si estas sobrepasan los límites, sí cabe la agresión ilegítima y por tanto hay legítima defensa. 
Asimismo, si la agresión producida genera una suerte de arrepentimiento del agresor frente al agredido, este puede considerar su aceptación o no, producido el primero desaparece en cierta medida el tercer requisito, dado que se aceptaría como agresión legítima.

Considero pertinente que cuando se trata de agresiones verbales pasivas y mutuas, podría cumplirse el tercer requisito, ello cuando sobrepase los límites permisibles entre el agresor y el agredido, por ejemplo: si una mujer con justa razón reclama pasivamente a un hombre sobre el incumplimiento de una pensión alimenticia o alguna deuda pendiente, y este actúa con una conducta agresora al emplear palabras soeces, empujones, etc., que superen una real dimensión de agresividad verbal, física o psicológica, la primera está en todo el derecho de reaccionar en defensa de su integridad moral, psicológica o física, dando así lugar a un puñete, un manotazo, una patada, etc. En tal escenario, se produce una falta de provocación suficiente del que hace la defensa.

\subsubsection{Provocación suficiente}

La provocación suficiente implicaría lo bastante grave como para provocar una reacción agresiva, ello supone quitar o despojar al agresor-provocador del derecho a una acción defensiva. Es decir, en dicha agresión debe ser objetivamente pronosticable un ataque o amenaza. Entonces, conlleva a descalificar conductas leves, insignificantes, burlas, chistes, etc., en estos casos no es aceptable ejercer la legítima defensa. Señala Peña Cabrera (2011) que quedan fuera de este marco las reacciones explosivas de quien recibe una ofensa verbal y ejecuta una conducta violenta, v. gr., quien ante los piropos que recaen sobre su pareja, reacciona disparando un arma de fuego, por lo que el provocador no está obligado a soportar dicha reacción agresiva, al estar amparado por la legítima defensa. 


\subsubsection{Provocación intencional}

Se excluye una conducta intencional, deliberada o premeditada de quien inicia la provocación para darse una reacción agresiva del provocado, no se puede poner pretextos o motivos injustificados que hagan permisible su reacción inmediata. Por ejemplo, si una persona busca razones o motivos para ser agredido y considerar que existe una agresión ilegítima, una provocación intencional, etc., pierde toda posibilidad de invocar una legítima defensa. Es decir, no será viable emplear la legítima defensa cuando medie una agresión injustificada, para luego ser considerada agresión ilegítima.

\subsubsection{Legislación comparada}

Para el Código Penal español:

\section{Artículo 20}

Están exentos de responsabilidad criminal:

[...]

4..$^{\circ}$ El que obre en defensa de la persona o derechos propios o ajenos, siempre que concurran los requisitos siguientes: $[\ldots]$

Tercero. Falta de provocación suficiente por parte del defensor (Ley Orgánica 10/1995).

De acuerdo con el Código Penal ecuatoriano:

Artículo 33.- Legítima defensa.

Existe legítima defensa cuando la persona actúa en defensa de cualquier derecho, propio o ajeno, siempre y cuando concurran los siguientes requisitos:

[...]

3. Falta de provocación suficiente por parte de quien actúa en defensa del derecho. 


\section{CONSECUENCIAS ADVERSAS PROPIAS}

En principio, si la legítima defensa es ejercida en cumplimiento de los tres requisitos que exige el Código Penal vigente, estaríamos ante una causa de justificación acorde a derecho; por tanto, quien hace la defensa está exento de responsabilidad penal. Si por alguna circunstancia no se cumpliese algún requisito legal, estaríamos ante una figura de legítima defensa incompleta o imperfecta. En estos supuestos, habrá una responsabilidad penal atenuada, según la cual se fijará una pena por el mínimo legal, lo que corresponde determinar al órgano jurisdiccional.

Asimismo, activar la legítima defensa como derecho fundamental, implica ser muy cuidadoso ante una agresión ilegítima de un tercero, debido a que a veces el agredido o víctima termina siendo más perjudicado, por ejemplo: podría fallecer o tener algún daño corporal en el ejercicio de su derecho legítimo.

Por ende, estar ante un peligro actual e inminente, nos faculta a ejercer la legítima defensa en salvaguarda de los bienes y derechos. En tal escenario, se deben medir las posibles consecuencias adversas que conlleva, por ejemplo: si solo está en riesgo la integridad de quien hace la defensa o, también, de terceras personas, dado que se ha visto ocasiones en que el perjudicado es un tercero, y no el agredido. Por ello, surge la pregunta: ¿quién se hace responsable por las consecuencias ajenas al ejercicio de la legítima defensa? Como respuesta a ello se considera viable ejercer en contra del agredido, ahora bien, si por alguna circunstancia se imposibilita al agresor, deberá asumir el agredido.

\section{CONSECUENCIAS ADVERSAS IMPROPIAS}

Este apartado es muy controvertido para quien apoya al tercero con la legítima defensa, debemos ser muy cuidadosos o cautelosos 
para calificar los tres requisitos de la legítima defensa. Así, ante una posible o aparente pelea entre parejas o amigos, no se puede suponer o antelar que existe un peligro de algún bien jurídico de la víctima, cuando en realidad tal vez es un juego, una broma, etc. En tal escenario, no se podría invocar la legítima defensa de terceros.

Asimismo, surge una de las interrogantes: ¿cuándo es apropiado actuar en legítima defensa de terceros? Al respecto, no ha sido desarrollado por la doctrina penal, existe escasa fuente bibliográfica, entonces, considero y reiterando supra, quien apoya a un tercero con la legítima defensa debe ser muy cuidadoso y no caer en exceso de la legítima defensa o legítima defensa putativa. Lo que implicaría tener responsabilidad penal por el hecho.

\section{TOMA DE POSTURA GENERAL}

Primero, si bien es cierto que todos tenemos el derecho a la legítima defensa en pro de salvaguardar bienes jurídicos propios o de terceros, también implica un riesgo adverso al ejercicio de tal derecho. Ello en razón a lo expuesto anteriormente.

Segundo, de existir algún riesgo adverso como una muerte indirecta de terceros o algún daño, lesión, etc., este debe ser asumido por la persona que ejerce la legítima defensa; porque si el agresor fallece, no habría contra quién efectuar alguna suerte de reparación civil, más aún, sabiendo que en el mundo del hampa los delincuentes no cuentan con recursos o familiares cercanos. También debe ser asumido por el agresor, si por alguna circunstancia viviese ante el enfrentamiento defensivo.

Tercero, en dicha situación se está dejando indefensas a las víctimas que han sufrido alguna lesión o daño en su integridad personal o patrimonial. En estos casos se presenta algún gasto médico, funerario u otros. 
Cuarto, cuando se emplea la legítima defensa surgen tres cuestiones a saber: a) puede producirse algún resultado adverso para quien hace la defensa y para el agresor, como lesiones, entre otros; b) pueden ser perjudicadas ambas partes, el agresor y la víctima; c) puede no presentarse algún daño o lesión en ambas partes, agresor y víctima, o resultar algún daño a una tercera persona.

\section{JURISPRUDENCIA NACIONAL}

Sirva como ejemplo de los requisitos de la legítima defensa, la siguiente cita:

Primer presupuesto: agresión ilegítima. Se trata de un comportamiento dirigido a lesionar o poner en peligro un bien legalmente protegido, donde el adjetivo ilegítimo es utilizado en el texto legal para calificar a la agresión de ilícito e injusto, contrario al orden jurídico. De tal forma que la agresión debe ser inminente, actual o presente.

[...]

Segundo presupuesto: necesidad racional del medio empleado para impedirla repelerla. Se trata - señala la Corte- de una apreciación de valor con referencia a la justicia y la equidad. La racionalidad de la defensa se determina apreciando la proporcionalidad entre el peligro propio a la agresión y la acción de defenderse; es decir, entre las condiciones, instrumentos y riesgos de la agresión y los propios del comportamiento defensivo.

$[\ldots]$

Tercer presupuesto: falta de provocación suficiente de quien hace la defensa. Se trata de una actitud especial de quien se defiende, esto es, de poner cuidado en comportarse de manera tal que no origine, de parte de cualquier persona, una reacción contra él. La apreciación del carácter suficiente de la provocación debe hacerse mediante un juicio objetivo de valor, no puede depender, por ejemplo, de la extremada susceptibilidad o irritabilidad del sujeto en cuestión (Corte Suprema de Justicia de la República, 2018, f. j. 8). 


\section{CONCLUSIONES}

La legítima defensa constituye un derecho fundamental de las personas, que goza de protección constitucional y legal, y se encuentra regulada en el artículo 2, inciso 23, de la Constitución Política vigente. Asimismo, está normada en el artículo 20, inciso 3, del Código Penal vigente, bajo la nomenclatura de eximentes de responsabilidad penal.

La agresión ilegítima opera como primer requisito de la legítima defensa frente a la vulneración de bienes jurídicos propios o de terceros. La conducta del agraviado está amparada a derecho. Solo es posible accionar la conducta defensiva cuando medie una circunstancia de ilegitimidad, real, actual o inminente.

La defensa necesaria es entendida como una defensa adecuada para frenar la agresión ilegítima del agresor. Es decir, entre los múltiples medios o formas de repeler la agresión, el agredido debe elegir la menos lesiva para proteger los bienes jurídicos tutelados. Ello en salvaguarda de los derechos e intereses personales.

La falta de provocación es una conducta desplegada por el agresor, que conlleva a una conducta previsible del agredido. Es decir, quien hace la defensa no debe actuar y provocar al agresor. Asimismo, la provocación es una acción u omisión anterior a la agresión ilegítima.

Del mismo modo, si por alguna circunstancia en el ejercicio de la legítima defensa, se presentan hechos ajenos no predecibles, como el daño, la lesión o la muerte de alguna persona, ello debe ser asumido por el agresor, y eventualmente por el agredido, de esta manera no se deja desamparadas a posibles víctimas ajenas. La finalidad de esto es básicamente resarcir los daños y perjuicios ocasionados. 
Finalmente, para validar la configuración y el cumplimiento de los requisitos de la legítima defensa debe concurrir obligatoriamente lo señalado en el artículo 20, inciso 3, del Código Penal vigente. Caso contrario, estamos frente a la figura de la legítima defensa incompleta o exceso de esta.

\section{REFERENCIAS}

Berdugo, I., Arroyo, L., García, N., Ferré, J. y Serrano, J. (1999). Lecciones de derecho penal. Parte general (2. ${ }^{\mathrm{a}}$ ed.). Praxis.

Cerezo, J. (1998). Curso de derecho penal español. Parte general. Tomo II. Tecnos.

Congreso de la Nación Argentina (1984). Ley n. ${ }^{\circ}$ 11.179. Código Penal de la Nación Argentina. Buenos Aires: 27 de agosto de 1984.

Congreso de la República de Colombia (2000). Ley n. ${ }^{\circ} 599$. Código Penal Colombiano. Bogotá: 24 de julio de 2000.

Congreso Nacional de Chile (1874). Código Penal. Santiago: 12 de noviembre de 1874 .

Corte Suprema de Justicia de la República (2018). Recurso de nulidad n. ${ }^{\circ}$ 910-2018. Lima Este. Sala Penal Transitoria. Lima: 5 de diciembre de 2018.

Cuello, E. (1976). Derecho penal. Parte general. Tomo I. Bosch.

García, P. (2019). Derecho penal. Parte general (3. a ed.). Ideas Solución Editorial.

Jefatura del Estado (1995). Ley Orgánica 10/1995, de 23 de noviembre, del Código Penal. Madrid: 23 de noviembre de 1995. Jiménez, L. (1939). Tratado de derecho penal. Tomo I. Losada. 
Luzón, D. (2006). Aspectos esenciales de la legítima defensa. BdeF.

Mir, S. (2008). Derecho penal. Parte general. BdeF.

Muñoz, F., y García, M. (2010). Derecho Penal. Parte general. Tirant lo Blanch.

Peña, A. (2011). Derecho penal. Parte general. Tomo I. Idemsa.

Pérez, J. (2016). Las 15 eximentes de responsabilidad penal. Gaceta Jurídica.

Poder Ejecutivo (1991). Decreto Legislativo n. ${ }^{\circ}$ 635. Código Penal. Lima: 8 de abril de 1991.

República del Ecuador. Asamblea General (2014). Código Orgánico Integral Penal. Quito: 3 de febrero de 2014.

Revilla, P. (2015). Derecho a la legítima defensa. En Gutiérrez, W. (dir.), La Constitución comentada. Tomo I (3. ${ }^{a}$ ed.) (pp. 350-359). Gaceta Jurídica.

Roxin, C. (1997). Derecho penal. Parte general. Tomo I. (trad. Diego Luzón, Miguel Díaz y Javier de Vicente). Civitas.

Sandoval, J. (1994). Legítima defensa: los derechos defendibles. Temis.

Villegas, E. (2014). La legítima defensa en el derecho penal peruano. En Montoya, C. (dir.), Las causales eximentes de responsabilidad penal. Gaceta Jurídica.

Welzel, H. (1956). Derecho penal. Parte general. Roque Depalma Editor.

Zambrano, A. (2006). Derecho penal. Parte general (3. ${ }^{a}$ ed.). ARA Editores. 